\title{
LAS RELACIONES INTERADMINISTRATIVAS EN LA LEY REGULADORA DE LAS BASES DE REGIMEN LOCAL *
}

\author{
por \\ Arturo Fontana Puig \\ Técnico Superior de la Generalidad Valenciana
}

SUMARIO: I. INTRODUCCION.-II. SU JUSTIFICACION: LA EFICACIA DE LAS ADMINISTRACIONES PUBLICAS.-III. CARACTERES ESENCIALES DEL SISTEMA DE RELACIONES INTERADMINISTRATIVAS: 1 . LA LIBERTAD DE LOS ENTES LOCALES. SUS LfMITES: A) Los intereses generales o comunitarios. B) La capacidad de gestión administrativa. 2. EL RESPETO AL EJERCICIO LEGITIMO DE LAS PROPIAS COMPETENCIAS. 3. LOS MECANISMOS DE INFORMACIÓN: A) Los mecanismos de información en las relaciones de cooperación. B) Los mecanismos de información en las relaciones de coordinación.-IV. LAS RELACIONES DE COOPERACION: 1. TÉCNICAS RELACIONALES DE COOPERACIÓN: A) Información. B) Asesoramiento técnico o administrativo. C) Asistencia técnica. D) Ayuda financiera. E) Convenios administrativos. F) Consorcios, Mancomunidades y Sociedades. G) Técnicas de Delegación. 2. TÉcNiCAS ORGÁNICAS DE COOPERACIÓN: A) La Comisión Nacional de Administración Local. B) El Consell Valencià d'Administració Local. C) Las Comisiones Territoriales y los órganos de colaboración.-V. LAS RELACIONES DE COORDINACION: 1. EL ART. 59 DE LA LRBRL: A) Presupuestos habilitantes. B) Requisitos y contenido. C) Limites. 2. LA LEY DE

- Este trabajo sirvió como Ponencia en las Jornadas de Formación Básica Mu. nicipal que se celebraron en Valencia en junio de 1987. 
Coordinación de las Diputaciones Provinciales. 3. Otras técNICAS DE COORDINACIÓN.-VI. LAS RELACIONES DE COLISION: 1. POR CONDUCta Pasiva. 2. POR CONDUCta activa.-VII. CONCLUSIONES.

\section{LAS RELACIONES INTERADMINISTRATIVAS EN LA LEY 7/1985}

\section{INTRODUCCION}

La Ley Reguladora de las Bases de Régimen Local (en adelante, LRBRL) dedica el Capítulo II de su Título $\mathrm{V}$ a las «Relaciones interadministrativas", tema sobre el que debe versar esta Ponencia.

Conviene precisar que el estudio que vamos a realizar no contiene todas las relaciones administrativas que pueden darse entre las distintas Administraciones Públicas. Por un lado, se excluyen las relaciones que por su naturaleza no pueden ser materias propias de esta Ley, como las relaciones Estado-Comunidades Autónomas; de otro, también quedan fuera de nuestro ámbito de estudio determinadas técnicas relacionales que se desarrollan entre Entidades locales, como la cooperación Diputación-Municipios o las Mancomunidades de estos últimos.

Finalmente, también queda al margen de nuestro campo de análisis el estudio de determinadas relaciones de conflictos, como lo es la impugnación de actos y acuerdos de las Entidades locales por parte de la Administración estatal o autonómica.

De lo expuesto se deduce que sólo nos vamos a centrar en el estudio de determinadas técnicas relacionales que se dan entre la Administración del Estado o de las Comunidades Autónomas, y las Entidades locales -Diputaciones y Ayuntamientos-.

Por último, puede pensarse que es un tema teórico o predominantemente técnico, carente de importancia en cuanto a su trascendencia práctica, pero ello está muy lejos de la realidad como vamos a comprobar.

\section{LA EFICACIA DE LAS ADMINISTRACIONES PUBLICAS}

Se ha señalado con razón que, pese a la literal afirmación de que la eficacia es un principio de actuación de la Administración 
(art. $103 \mathrm{CE}$ ), la misma no es un verdadero principio, sino un criterio general que expresa una aspiración de los constituyentes (1), el fin a que debe tender toda actuación administrativa (2).

Si esta aspiración debe ser siempre buscada para conseguir más y/o mejores con menos costos, en épocas de larga crisis económica esta necesidad se acentúa ante el peligro de una quiebra de la legitimidad del Estado Social de Derecho (3). Tal vez por ello también se recoge en el artículo $6 .^{\circ}$ LRBRL.

La Administración - por definición- va a gestionar recursos escasos con la finalidad de conseguir unas determinadas metas, unos determinados objetivos sociales (educativos, sanitarios, culturales, deportivos, etc...), y desde una perspectiva económica se nos revela que cualquier iniciativa de una unidad de decisión económica va a influir - directa o indirectamente- en las otras unidades de decisión (4).

La eficacia en el actuar cotidiano de todas las Administraciones Públicas —estatal, regional y local- se nos revela tal vez como el único camino posible para utilizar mejor los recursos escasos de los Poderes públicos.

Si las decisiones económicas de las Administraciones Públicas -dentro del ámbito de sus competencias- van a condicionar la consecución del nivel deseado o posible de bienestar en la sociedad, es por ello necesario que en un Estado complejo con diversos centros de decisión se articulen los cauces que permitan tomar las decisiones, de forma individual o integrada, más adecuadas en cada momento.

A esta finalidad responden las diversas técnicas relacionales que se establecen en la Ley $7 / 85$, y que podemos agrupar, para su mejor comprensión, en los siguientes grupos:
A) Relaciones de Colaboración.
B) Relaciones de Coordinación.
C) Relaciones de Colisión.

(1) Baena del Alcazar, Mariano: Organización Administrativa, Tecnos, Madrid, 1984 , pág. 85.

(2) Escuin Palop, Vicente: «La Administración del Estado en la Constitución», en Estudios sobre la Constitución española de 1978, Universidad de Valencia, Valencia, 1980, pág. 286.

(3) Garcta Cotarelo, Ramón: Del Estado del Bienestar al Estado del Malestar, Centro de Estudios Constitucionales, Madrid, 1986, pág. 181 y sigs.

(4) LANGE, Oscar: El campo y método de la Economia, Universidad de Valencia, página 31 y siguientes. 
No obstante, antes de entrar en el análisis de cada uno de los apartados enunciados, se impone reseñar los rasgos básicos sobre los que descansa el entramado de las relaciones interadministrativas.

\section{CARACTERES ESENCIALES DEL SISTEMA}

Los pivotes sobre los que gravitan las distintas técnicas relacionales y que constituyen, a su vez, las claves para la comprensión del sistema establecido, son las que a continuación exponemos brevemente.

\section{La libertad de los ENTES locales. SUS Lfmites}

Las Entidades locales gozan de autonomía para la gestión de sus respectivos intereses, locales o provinciales (art. $137 \mathrm{CE}$ ). Por ello, las Entidades locales pueden acordar con una gran dosis de libertad el desarrotlo de aquellas actuaciones que más les convenga.

Pero la Constitución sienta el mismo principio respecto de las Comunidades Autónomas para la gestión de sus intereses regionales o comunitarios (art. $137 \mathrm{CE}$ ), mientras que los intereses generales quedan confiados a la Administración del Estado.

Por ello, la libertad de actuación de las Entidades locales - $m u$ tatis mutandi como la de cualquier otra Administración- sufrirá al menos limitaciones en dos sentidos. Por la definición de las competencias de las otras Administraciones; es decir, por la definición legal de los intereses comunitarios y generales; y, en segundo lugar, por la capacidad real de gestión que se asigne a las Entidades locales.

\section{A) Los intereses generales o comunitarios}

Los primeros se articulan en el artículo 149 de la CE; los segundos, los intereses comunitarios, en los artículos 31 a 41 de nuestro Estatuto de Autonomía.

Lo mismo les ocurrirá en su día a las Entidades locales cuando tengan definido su arco competencial. La Ley $7 / 85$ es el primer paso en ese sentido, luego habrá que estar a la Ley de la Generalidad sobre Gobierno local, $y$ en tercer lugar a las leyes sectoriales del 
Estado y de la Generalidad que definirán intereses generales o comunitarios, y locales.

No podemos dudar del hecho de que los intereses generales y comunitarios se superponen, y en este sentido se sitúan por encima, a los intereses locales. La Ley $7 / 85$ hubiera podido establecer que en caso de yuxtaposición de un interés general o comunitario frente al interés local prevaleciera el primero sin más. No lo ha hecho así. Ha establecido que ambas Administraciones - la estatal o autonómica- y la local deben coordinarse. La Entidad local no podrá decidir libérrimamente lo que le convenga, pero expresará su parecer y luego tendrá que ejecutar la función que se le asigne.

Coordinar significa que decide el superior, pero en modo alguno que la Entidad local quede despojada de sus competencias y funciones. El interés local se integrará como parte de un interés comunitario o general que lo asume y, por tanto, nunca lo anula.

Por lo demás, las Entidades locales no sólo gestionarán una parte de la materia o función coordinada, sino que además podrán desarrollar libremente acciones complementarias a las coordinadas para satisfacer su interés local.

Por último, incluso en situaciones de colisión, la Entidad local puede defender sus intereses ante los Tribunales de Justicia, que serán los que de forma imparcial decidirán sobre el conflicto planteado.

\section{B) La capacidad de gestión administrativa}

La Constitución es generosa al afirmar la autonomía de las Entidades locales, no respecto de sus intereses propios, sino en relación a todos sus intereses (5).

Ello se consigue básicamente de dos mecanismos. Afirmando en primer lugar su capacidad de autoorganización, a través de los $\mathrm{Re}$ glamentos orgánicos, más allá de lo que dispongan las normas legales de las Comunidades Autónomas (art. 20-2..$^{\circ}$ LRBRL); y, en segundo término, asegurando su intervención en cuantos asuntos afecten a sus círculos de intereses (art. 2..$^{\circ}$ LRBRL).

Ahora bien, esa participación en los asuntos públicos que les conciernan va a estar directamente condicionada por la capacidad

(5) Parejo Alfonso, Luciano: ala Autonomía Local», REVLA, núm. 229, IEAL, página 52 y sigs. 
económica -y organizativa- con que cuenten los Entes locales para desarrollar políticas locales propias.

Una Administración local como la española, que gestiona alrededor de un 9,14 por 100 del gasto público total (6), y que un 72,1 por 100 de lo que le corresponde (7) ha de destinarlo a gastos corrientes, no es lógico que pueda desarrollar grandes políticas de inversión pública, sino que deberá ceñirse más bien a lo urgente, lo inaplazable.

En otras palabras, en principio no resulta congruente pensar que van a florecer en la práctica auténticas acciones coordinadoras de las Administraciones superiores para aunar esfuerzos y criterios divergentes tomados por sujetos distintos, al tener, al menos uno de estos sujetos - los Municipios- una esfera de actuación prestacional bastante limitada.

La realidad muchas veces nos demuestra que son las Entidades locales las que se suman a los Planes que elaboran las Administraciones superiores con la finalidad de financiar sólo una parte de los costos de la inversión. El caso de los Municipios y los Planes Provinciales de Obras y Servicios es, en este sentido, el paradigma.

\section{El RESPETO AL EJERCICIO LEGfTIMO DE LAS PROPIAS COMPETENCIAS}

Este principio se configura, a nuestro entender, como el punto de tensión de todo el sistema sobre el que se articulan las técnicas relacionales.

No sólo deben las Entidades locales respetar el ejercicio legítimo de las competencias estatales y autonómicas por parte de la Administración del Estado y la de la Comunidad Autónoma, sino que éstas -el Estado y la CA- han de respetar el ejercicio legítimo de las competencias municipales y provinciales [art. 55.a)].

Ciertamente no es fácil determinar las competencias propias que corresponden a los Entes locales. De hecho, la mayoría de ellas están por determinar a través de las leyes sectoriales que dicten el

(6) Datos referidos a 1982 , en «Una nota sobre la gestión fiscal y financiera de los Ayuntamientos», por Benavides y FariÑas, en el II Congreso de Economía y de Economistas de España.

(7) Dato referido a la media de los Municipios de la Comunidad Valenciana. Vid. Pressupostos municipals, 1986, Conselleria d'Administració Pública, Valencia, 1987, página 570. 
Estado y de las Comunidades Autónomas (8). No obstante, en virtud del artículo 2. ${ }^{\circ}$ LRBRL tanto el Estado como la Generalidad han de traducir en dichas leyes los intereses de los Entes locales en competencias, o al menos, en funciones específicas que aseguren su derecho a intervenir en cuantos asuntos les afecten (9).

Es obvio que de este principio se derive la libertad de los Entes locales para decidir e incidir, y según qué intensidad, en los distintos ámbitos de la realidad según el bloque de competencias que se les otorga. Mantener otra postura supondría vaciar la autonomía administrativa de la que están dotados (10), salvo las reglas de cierre del sistema.

A la afirmación anterior es preciso hacer dos matizaciones. De un lado, los Municipios no son libres para prestar o no los servicios públicos calificados como obligatorios en el artículo $26 \mathrm{LRBRL}$, sino que van a estar obligados a ello. De otro lado, las Entidades locales no sólo van a incidir en los ámbitos materiales en los que se define su competencia, sino que pueden ejercer sus funciones más allá en virtud de la cláusula gèneral de apoderamiento que recoge el artículo 25-1. ${ }^{\circ}$ LRBRL (11).

Por lo demás, hay que señalar que una Administración verá más respetado el propio ejercicio de sus competencias cuanto más tenga en cuenta o pondere la totalidad de los intereses públicos implicados al tomar sus propias decisiones [art. 55.b)].

Con razón se ha dicho que la innovación legislativa en este caso es destacable (12), pues supone un laudable esfuerzo para integrar en los intereses propios los intereses generales de toda la colectividad. $\mathrm{Su}$ fundamento se encuentra en el principio de unidad del sistema, y no puede señalarse que su incumplimiento sea intrascendente ya que puede evitar ulteriores medidas coordinadoras si se producen actuaciones disfuncionales en ámbitos competenciales concurrentes.

Ahora bien, para conseguir la máxima eficacia en el desarrollo

(8) Climent BarberA, Juan: Legislación básica de Régimen local, Conselleria d'Adnistració Pública, Valencia, 1987, pág. 221.

(9) Parejo Alfonso, Luciano, op. cit., pág. 60.

(10) Por ello, como afirma la Sentencia del Tribunal Constitucional de 2 de febrero de 1981, «... (el art. 137) exige que se dote a cada Ente de todas las competencias propias y exclusivas que sean necesarias para satisfacer el interés respectivo», DE LOPE, Mercedes, y SANZ FERNÁNDEZ, Luis, en Administración Local y Constitución, IEAL, Madrid, 1986, pág. 14.

(11) Entrena Cuesta, Rafael: Curso de Derecho Administrativo, volumen I/2, Tecnos, Madrid, 1981, pág. 220.

(12) Publicaciones Abella: Nuevo Régimen local, Madrid, 1985, pág. 443. 
de las competencias propias al tiempo que se respeta el ejercicio de las ajenas, y para aunar esfuerzos en ámbitos competenciales concurrentes, es necesario saber qué acciones públicas se están llevando a cabo y cuáles piensan emprenderse. Es necesario que existan unos canales de información permanentes y dinámicos entre todas las Administraciones.

\section{LOS MECANISMOS DE INFORMACIÓN}

Suele hacerse hincapié en el concreto deber de remisión por parte de las Entidades locales de copia o extracto de los actos y acuerdos de las mismas a la Administración del Estado y de la Comunidad Autónoma que establece el artículo 56-1. ${ }^{\circ}$ LRBRL, como un instrumento previo que posibilita el control de legalidad (13).

Para nosotros es mucho más importante señalar que la información entre las distintas Administraciones es un derecho-deber (14) permanente $u$ ordinario entre todas ellas, que recorre como una médula las distintas situaciones de cooperación, coordinación y colisión en que pueden encontrarse dos Administraciones Públicas. No es casual, pues, que este principio aparezca regulado en las Dispo. siciones Generales (art. 10-1. ${ }^{\circ}$ LRBRL).

A) Los mecanismos de información en las relaciones de cooperación

Los mecanismos a través de los cuales se define este derechodeber de información pueden ser de indole muy variada:

a) Comunicación o informe, previa petición razonada, de todos aquellos datos o extremos sobre la gestión que se realiza, o se piensa ejecutar, y que pueda incidir en los ámbitos competenciales de otra Administración [art. 55.c)].

b) Comunicación de oficio de los acuerdos de cooperación, convenios o consorcios, a aquellas otras Administraciones que no hayan intervenido pero que sean interesadas (art. 57-2. $)$.

c) La información que se derive del libre acceso a los Registros

(13) Garcfa-Escudero Marquez, Piedad, y Pendas Garcfa, Benigno: Nuevo Régimen local español, Praxis, Barcelona, 1985, pág. 283; LLISET BorRell, Francisco: Manual de Derecho local, Publicaciones Abella, Madrid, 1985, págs. 257-258.

(14) Climent Barbera, Juan, op. cit., pág. 221. 
públicos (art. 105-2. $\mathrm{CE}$ ), y de la exhibición de toda clase de documentación y expedientes administrativos (arts. 62 y 63 LPA).

d) En concreto, el acceso de las Entidades locales a los instrumentos de planificación, programación y gestión de obras y servicios que elabore el Estado y la Comunidad Autónoma (art. 55-3 LRBRL).

e) La información espontánea que se genere a través de medios informales, como sesiones de trabajo, conferencias sectoriales, acceso e intercambio de estatutos, encuestas, etc. (15).

En definitiva, no es exagerado afirmar que la LRBRL desea $y$ quiere una reciproca y constante información (art. 57-8, in fine, LRBRL) entre los diversos niveles de Administración, información al servicio de una sociedad con problemas graves en tiempos de crisis económica que necesita que sus Administraciones sean más eficaces en todos sus campos de actuación.

Por último, debe señalarse que en la medida que todas las Administraciones mantengan esa constante información sobre sus actividades, menor será el recurso a eventuales técnicas de coordinación, pues no olvidemos que en la definición de los intereses propios - sean generales, comunitarios o locales- ha de ponderarse el interés de los otros.

B) Los mecanismos de información en las relaciones de coordinación

En estos tipos de relaciones es donde la información deja de ser un derecho y se convierte en un deber, incluso una carga.

a) Aquí tiene su encuadre el deber de las Entidades locales de remitir a la Administración del Estado y de la Comunidad Autónoma copia o extracto de sus actos o acuerdos, así como ampliación de la información a que se refieren (arts. 56-1. ${ }^{\circ}$ y 64 LRBRL).

Opcionalmente entendemos que también es posible, y tal vez muy conveniente, pedir la exhibición de la documentación o expediente completo.

b) El deber de aquella Administración que elabore instrumentos de planificación (entre ellas las Entidades locales, vid. art. 59-3. ${ }^{\circ}$ LRBRL) de informar a las otras del contenido de los mismos a los

(15) Alvarez Rico, Manuel: Principios constitucionales de Organización de las Administraciones Públicas, IEAL, Madrid, 1986, pág. 109. 
efectos de armonizar los intereses públicos afectados (art. 58-2. LRBRL).

La articulación de este deber de información no puede reducirse al mero cumplimiento de trámites administrativos, de información pública o de audiencia, sino que ha de darse traslado del documento de planificación en su integridad (16).

c) Las leyes sectoriales del Estado o de la Generalidad que coordinen la actividad de la Administración local, de una forma u otra deberán prever los canales de información precisos que garanticen la consecución de la pretendida coordinación. La Ley ha de fijar tanto las «condiciones» como los «límites» o las «modalidades de control» que competan a los Parlamentos estatal o regional, o a los Ejecutivos estatal o regional (art. 59-1. ${ }^{\circ}$ y 3..$^{\circ}$.

d) Por último, en el supuesto de que se delegue el ejercicio de competencias, el ente delegante puede requerir las informaciones que estime previstas, o enviar Comisionados para obtenerlas directamente (art. 27-2. ${ }^{\circ}$ LRBRL).

\section{LAS RELACIONES DE COOPERACION}

Las relaciones de cooperación o colaboración son las relaciones normales que deben existir entre dos Administraciones, incluso cuando ejercitan competencias propias pues, como hemos visto, la limitada capacidad económica de los Entes locales, sumado a la conciencia de que los intereses locales han dejado de tener este carácter, conduce, según señala ENTRENA CUESTA, a la proliferación de lo que se ha denominado una "Administración mixta" en la que nos encontramos con servicios que se prestan gracias a la colaboración de dos o más Administraciones (17).

En todo caso, es importante resaltar que la cooperación en principio parte de la afirmación inicial de la igualdad entre los dos o más sujetos que se coordinan, por lo que se afirma taxativamente que la misma ha de revestir carácter voluntario (art. 57-7. ${ }^{\circ}$ ).

También debemos advertir, desde el punto de vista práctico, que es conveniente para las Entidades locales que articulen sus relaciones bajo el prisma de la cooperación y la colaboración mutuas ya

(16) Publicaciones Abella, op. cit., pág. 454.

(17) Op. cit., págs. 199-200. 
que no sólo podrán beneficiarse de ayudas económicas, técnicas y administrativas, esporádica o continuamente, sino que evitarán en algunos casos la posible utilización de técnicas coordinadoras. Es, por así decirlo, la regla general.

Podemos establecer, a efectos expositivos, la siguiente distinción entre las diversas técnicas de cooperación: 1. Técnicas relacionales, y 2. Técnicas orgánicas.

\section{TÉCNicas RELACIONALES DE COOPERACión}

El mismo artículo 57-1. al decir que la misma se desarrollará "bajo las formas y en los términos previstos en las leyes", nos anuncia la diversa variedad de técnicas que, por su naturaleza, se encuadran en este epígrafe, como son:

A) Los cinco mecanismos de información mencionados en el epígrafe III, 3, A), a saber: Comunicación previa petición de aquellos datos o extremos que atañen a competencias compartidas, comunicación de oficio de los acuerdos de cooperación, convenios y consorcios, información que se derive del acceso a los Registros, a la documentación administrativa y a los instrumentos de planificación, y por último, la información espontánea que se genere a través de medios informales.

B) El simple asesoramiento técnico o administrativo (18) sobre cualquier problema que se suscite, y que conduce normalmente a la petición de un informe.

C) La asistencia técnica, que se concretará en la elaboración de estudios y proyectos de ejecución de obras, prestación de servicios o cualquier otra actividad propia o común con las Entidades locales (art. 62 del Real Decreto legislativo 781/1986, de 18 de abril, en adelante, TR).

D) La ayuda financiera que se llevará a cabo mediante subvenciones, eventuales o continuas, para ejecutar obras o prestar servicios locales (art. 63 TR).

E) La celebración de los convenios para el desarrollo de cualquier competencia compartida. Destaca de esta figura los límites tan amplios que posee, ya que el contenido contractual del mismo puede variar sobre cualquier materia, competencia o función común,

(18) Climent Barbera, Juan, op. cit., pág. 222. 
y consistir en determinaciones económicas, técnicas o administrativas como señalan los artículos 57.1..$^{\circ}$, Ley 7/85, y 69 TR (19).

F) La creación de Consorcios, Ente instrumental con personalidad jurídica propia formado por Administraciones de distinto nivel, de Mancomunidades de Municipios (20), así como la creación de Sociedades privadas.

G) También debemos incluir entre las técnicas relacionales de cooperación la delegación de la ejecución material de competencias estatales o autonómicas, y la delegación de competencias en general, pues aunque es una figura límite entre las técnicas relacionales y las reglas de atribución de competencias, requiere la aceptación expresa de la Entidad local (arts. $27-3 .^{\circ}$ LRBRL y 67-3. ${ }^{\circ}$ TR), y la oportuna dotación económica. También incluimos en este apartado el supuesto de gestión ordinaria de competencias comunitarias por parte de las Diputaciones Provinciales (art. 8. $0^{\circ}$ LRBRL).

\section{TÉCNICAS ORGÁNICAS DE COOPERACIÓN}

Tratamos en este apartado aquellos supuestos en los que se crean órganos institucionales para canalizar la cooperación entre las distintas Administraciones. Como veremos, su principal virtualidad va a consistir en intentar articular mecanismos válidos para que los problemas que afecten a las Entidades locales sean conocidos por las Administraciones del Estado y de la Generalidad.

\section{A) La Comisión Nacional de Administración Local}

Su existencia es necesaria, y se conceptúa como el órgano permanente para la colaboración entre la Administración del Estado y la Administración Local (art. 117-1..$^{\circ}$ LRBRL), por lo que su régimen jurídico se articuló a través del Real Decreto 2342/1985, de 4 de diciembre).

La preside el Ministro de Administración Local (art. 117-2.

(19) En parte, la amplitud con que se contempla la figura del convenio administrativo deriva de su propia naturaleza, y en parte también por la ausencia de una normativa legal con carácter general. Vid. Nuevo Régimen Local, Publicaciones Abella, cit., págs. $458-460$.

(20) Las técnicas de cooperación sitúan o parten del principio de igualdad de los dos Entes, lo que no excluye que ambas Administraciones sean iguales por na. turaleza. Es obvio que las Mancomunidades de Municipios suponen la cooperación voluntaria de dos o más de ellos para ejecutar una obra o prestar un servicio de su competencia (art. 44 LRBRL). 
LRBRL), y se compone de éste más 38 vocales, la mitad de ellos en calidad de representantes de la Administración del Estado [artículo 3-2. ${ }^{\circ}$ a) del Real Decreto 2342/1985], y la otra mitad en representación de las Entidades locales «que serán designados por la Asociación de Entidades locales con mayor implantación" - según reza el art. 3-2..$^{\circ}$ ) - del Real Decreto citado antes.

Esta fórmula de designación de los representantes de las Entidades locales ha sido duramente criticada por cuanto puede favorecer una representación única y «cuasi-oficialista» que lógicamente redundaria en perjuicio de sus funciones (21).

También hay que resaltar que en la misma participan representantes de las Comunidades Autónomas (art. 58-2. LRBRL), designados por los Presidentes de las Comunidades Autónomas, que serán convocados «cuando por la naturaleza de los asuntos a tratar, se estime que afecten o puedan afectar a las competencias de las CC.AA.» (art. 10-5. ${ }^{\circ}$ del Real Decreto 2342/1985).

Esta redacción es criticable porque pensamos que hubiera sido preferible articular una representación permanente de las CC.AA. ante la Comisión nacional, aunque es desde luego posible una interpretación amplia de dicha cláusula.

La Comisión Nacional de Administración Local se estructura o funciona en Pleno, en Comisión Permanente, o en Subcomisiones, de las que se crean tres: la Subcomisión de Régimen Financiero, la Subcomisión de Régimen de Personal y la Subcomisión de Colaboración.

Las funciones que desarrolla las podemos agrupar en tres apartados:

a) Efectuar propuestas y sugerencias al Gobierno en materia de Administración Local (art. 118-1. B B, LRBRL).

b) Emitir informes respecto a los Anteproyectos de Ley y de Reglamentos en cuanto afecten al régimen local, también respecto a los casos de disolución de los órganos de gobierno de una Entidad local, y por último, respecto de operaciones de endeudamiento. Este último apartado sólo tiene sentido si lo entendemos como sugerencia al Gobierno para que modifique la materia (art. 118-1. $\mathrm{A}$ ).

c) Ejercitar un derecho de petición, entendemos que normalmente al Gobierno, pues la Comisión se adscribe al Ministerio de Administración Territorial, para impugnar ante el Tribunal Cons-

(21) Garcfa-Escudero Márouez, Piedad, y Pendas Garcfa, Benigno, op. cit., pág. 287. 
titucional las Leyes del Estado o de las CC.AA. que estimen lesivas para la autonomía local (art. 119 LRBRL).

\section{B) El Consell Valencià d'Administració Local}

Como consecuencia de la naturaleza bifronte del régimen local, el artículo $58-1 .^{\circ}$ prevé la posibilidad de que las CC.AA. creen sus propios órganos de cooperación con las Entidades locales.

La Generalitat Valenciana ha materializado esta posibilidad a través del Decreto 99/1986, de 30 de julio, por el que se crea y regula el "Consell Valencià d'Administració Local».

De su régimen legal destacan los siguientes rasgos básicos:

Se conceptúa como el órgano para la colaboración entre la Generalitat y las Entidades locales valencianas (art. 1-2. ${ }^{\circ}$ del Decreto del Consell 99/1986), y con carácter provisional hasta que se apruebe la Ley Valenciana de Gobierno Local y Organización Territorial (art. 1-1. ${ }^{\circ}$ del Decreto 99/1986).

Con esta transitoriedad se pretende salvar la exigencia de que haya de aprobarse su creación mediante Ley (art. 58-1..$^{\circ}$ LRBRL), o al menos se definan por Ley sus características esenciales como es el caso de la Comisión Nacional de Administración Local, como es lo lógico suponer.

Se compone el Consell Valencià d'Administració Local de 30 miembros, el Presidente, que es el Conseller de Administración Pública, y 29 vocales, catorce de ellos en representación de la Generalitat, y quince en representación de los Municipios y Provincias valencianos (art. 4. ${ }^{\circ}$ del Decreto 99/1986).

Como vemos, la paridad de miembros es absoluta a diferencia de la Comisión Nacional de Administración Local, en la que la representación estatal cuenta con un voto más.

Los representantes de los Entes locales son propuestos por «los Entes locales y sus Asociaciones», lo cual mejora y puede evitar la monopolización de esta representación que en la Comisión nacional se busca expresamente.

Un aspecto negativo lo constituye el hecho de que no se prevé la participación de representantes de la Administración del Estado. No es obstáculo su designación reglamentaria (22) al tener cobertura

(22) No ha de señalarse la autoridad estatal concreta, pues ello es competencia de la Administración del Estado. Vid. Alvarez Rico, Manuel, op. cit., pág. 53. 
legal tal decisión en el artículo 58-2..$^{\circ}$ LRBRL. En todo caso, es una técnica de colaboración novedosa y deseable.

El Consell Valencià d'Administració Local se estructura en el Pleno (art. 4-1. ${ }^{\circ}$ ), en la Comisión Permanente (art. 5. $)$ que sólo ejerce las funciones que le delegue el Pleno (art. 7-2..$^{\circ}$ ), y las Subcomisiones de Régimen Financiero y de Colaboración (art. 6. $)$, que preparan el trabajo del Pleno o de la Comisión Permanente (art. $8^{\circ}$ ).

En cuanto a las funciones que puede desarrollar, el artículo 58-1. LRBRL ya señala que los órganos que creen las CC.AA. serán "únicamente deliberantes o consultivos", lo que sólo se explica en el sentido de que no pueden instar de los órganos constitucionalmente competentes que planteen recurso de inconstitucionalidad, ya que es la única función no consultiva (emisión de informes) ni colaboradora (efectuar sugerencias) de la Comisión nacional. Sin embargo, entendemos que esta limitación carece de virtualidad, ya que nada puede impedir que el Consell Valencià d'Administració Local "sugiera» al Consell de la Generalitat que plantee un recurso de inconstitucionalidad o que modifique una Ley autonómica poco respetuosa con la autonomía local.

En definitiva, las atribuciones que formalmente tiene atribuidas este Consejo consultivo son:

a) Efectuar propuestas y sugerencias entendemos que en materia de régimen local, si se quiere en especial en materia de cooperación, pero no sólo en materia de cooperación como parece.desprenderse de la lectura literal del artículo 2-2.0 del Decreto 99/1986.

b) Emitir informes a los Anteproyectos de Ley y demás disposiciones "en cuanto afecten a la Administración Local», a los Proyectos de Decreto que fijan las directrices de coordinación conforme a la Ley de Coordinación de las Diputaciones, y a los Planes Provinciales de Cooperación a las obras y servicios municipales (art. 2-1. del Decreto 99/1986).

En resumen, es de esperar que la futura Ley de la Generalitat sobre Gobierno local ratifique la concepción del Consell Valencià d'Administració Local como el órgano permanente de colaboración entre la Generalitat y las Entidades locales, conserve las mejoras técnicas que se han observado respecto a la Comisión Nacional de Administración Local (absoluta paridad de no representaciones, y contar con una representación de las Entidades locales más proporcional a sus asociaciones), e introduzca aquellas determinaciones 
que ayuden a mejorar la cooperación (facultad expresa de elaborar sugerencias sobre cualquier materia de régimen local, y posibilidad expresa de contar con representación estatal).

\section{C) Las Comisiones Territoriales y los órganos de colaboración}

Nos referimos aquí a la posibilidad de que por Ley estatal o regional se creen órganos de colaboración de naturaleza general o sectorial, de ámbito provincial o regional (art. 58-1. ${ }^{\circ}$ ), así como que por Ley estatal se creen Comisiones Territoriales presumiblemente con competencias ejecutivas o decisorias (art. 58-2..$^{\circ}$.

Como ya se ha señalado, la proliferación de órganos de colaboración puede resultar disfuncional (23), máxime cuando se aprecia una tendencia a que las leyes sectoriales establezcan diferentes órganos de colaboración o cooperación.

Los órganos de colaboración de carácter sectorial pueden tener alguna virtualidad, pero aun así también cabe flexibilizar la posibilidad de crear Subcomisiones por parte de los órganos de colaboración estudiados antes. Como señala MUÑoz MACHADO, un excesivo número de este tipo de órganos acabará planteando la necesidad de coordinación de ellos mismos (24).

Respecto a las Comisiones Territoriales con funciones decisorias, y por ello coordinadoras, en materia de inversiones (léase Fondo Nacional de Cooperación Municipal) y de prestación de servicios, traen su causa en las Comisiones Provinciales de Colaboración, sólo que el artículo 58-1..$^{\circ}$ LRBR las configura a escala regional. Si se decidiera su creación, en la Comunidad Valenciana deberá tener participación de la Generalitat dada la fuerte incidencia de la Ley de la Generalitat 2/1983, de 4 de octubre.

\section{LAS RELACIONES DE COORDINACION}

Las relaciones de coordinación, necesarias y normales entre dos Entes públicos con competencias concurrentes o compartidas, no constituyen la regla general en base a la que los mismos siguen sus relaciones. La Ley $7 / 85$ intenta constreñir las técnicas de coopera-

(23) Lliset Borreul, Francisco, op. cit., pág. 245.

(24) Muñoz Machado, Santiago: Derecho público de las Comunidades Autónomas, Civitas, Madrid, 1982, t. I, pág. 70. 
ción porque es consciente de que la coordinación en cierto sentido supone una alteración competencial. Por eso afirma que procede la coordinación cuando esta finalidad no se ha conseguido con las técnicas de colaboración hasta ahora examinadas (art. 59-1. $)$.

Como hemos dicho, la Administración coordinada seguirá disfrutando de cierto margen de libertad y limitadamente podrá hacer valer sus pretensiones, pero limitadamente porque la última palabra la tendrá la Administración coordinadora o superior (25).

\section{El artículo 59 de la LRBRL}

Para asegurar la coherencia de la actuación administrativa la Ley estatal o comunitaria sectorial podrá disponer la coordinación de la Administración Local si concurren determinadas circunstancias (art. 59-1..$^{\circ}$.

\section{A) Presupuestos habilitantes}

Los podemos sintetizar en estos enunciados:

a) Cuando la coordinación no pueda alcanzarse a través de técnicas relacionales voluntarias, o éstas fueran "manifiestamente» inadecuadas por la naturaleza de la materia [arts. 59-1..$^{\circ}$ y 55.a) y $b$ )].

b) Además se exige que la actividad o servicio trascienda el interés local o provincial, de forma tal que incida o condicione «relevantemente» los intereses comunitarios o los generales, o sean concurrentes o complementarios de los mismos (art. 10-2..$^{\circ}$ LRBRL).

\section{B) Requisitos y contenido}

Se han establecido los siguientes:

a) Ha de realizarse a través de Ley formal estatal o regional, la cual ha de precisar con suficiente detalle las condiciones y los límites particulares de la coordinación, y las modalidades de control que se reserven las Cortes Generales o las Asambleas regionales (art. 59-2..$^{\circ}$.

b) Se realizará en las leyes sectoriales que regulan la acción pública, y en relación a una materia, servicio o competencia deter-

(25) Climent BarberA, Juan, op. et loc. últ. cit. 
minados (art. $59-1 .^{\circ}$, incisos primero y segundo), para «la fijación de medios y de sistemas de relación que haga posible la información recíproca, la homogeneidad técnica en determinados aspectos y la acción conjunta» (26).

c) La Ley definirá los intereses generales o comunitarios, que se articularán a través de Planes sectoriales que determinarán los objetivos y las prioridades de la materia, servicio o competencia (art. 59-1..$^{\circ}$ inciso segundo), que elaborará el Gobierno de la Nación o el Gobierno regional (art. 59-1. ${ }^{\circ}$, inciso primero).

\section{C) Limites}

a) En la elaboración de los Planes sectoriales tendrán que participar las Entidades locales coordinadas (art. 59-1..$^{\circ}$, inciso primero).

b) En ningún caso podrá afectar la coordinación la potestad de autoorganización de los Entes locales (art. 62-2..$^{\circ}$.

c) La coordinación deberá justificarse en el hecho de asegurar la coherencia en la actuación de las Administraciones.

d) La coordinación no puede traducirse en órdenes concretas y ha de respetar un margen de libre decisión o discrecionalidad de las Administraciones sujetas a coordinación, sin el cual no puede existir verdadera autonomía (27).

\section{La Ley de Coordinación de las Diputaciones Provinciales}

Habida cuenta de que este tema será específicamente tratado por otro conferenciante, nos limitaremos a reseñar dos ideas básicas sobre esta Ley específica de nuestra Comunidad.

Desde la aprobación de nuestro Estatuto de Autonomía en 1982 se estableció el mandato a la Generalitat de coordinar las funciones propias de las Diputaciones Provinciales que fueran de interés general comunitario (art. 47-3. del Estatuto), lo cual supone de una parte que la escala de distribución de competencias no queda afectada, y de otra, que se han de establecer unas limitaciones a las competencias de las Diputaciones (28).

(26) STC 27/87, Fundamento jurídico 2.

(27) STC $27 / 87$, Fundamento jurídico $60^{\circ}$

(28) Climent Barbera, Juan, en Comentarios al Estatuto de Autonomía de la Comunidad Autónoma Valenciana, obra dirigida por Ramón MARTín MATEO, IEAL, Madrid, 1985, pág. 479. 
También el artículo 59-1. ${ }^{\circ}$ LRBRL parte de la idea de que pueden ser objeto de coordinación «en especial» el ejercicio de competencias de las Diputaciones Provinciales. Esta idea es el trasunto de la nueva estructuración vertical de poder que supone el Estado Autonómico, y del difícil equilibrio que en el mismo se atribuye a las Diputaciones Provinciales (29).

El mandato estatutario se cumplió con la promulgación de la Ley de la Generalitat Valenciana 2/1983, de 4 de octubre, de declaración de interés general de las Diputaciones, declarada en lo esencial ajustada al bloque de constitucionalidad por la STC 27/87, de 27 de febrero (30).

De la Ley de Coordinación de las Diputaciones nos interesa destacar estas peculiaridades:

a) Se declaran de interés general comunitario determinadas funciones de las Diputaciones, y este es un concepto más restringido que el de "materia, servicio o competencia» del artículo 59-1. segundo inciso. No es lo mismo, por ejemplo, coordinar la competencia de urbanismo que determinadas funciones urbanísticas.

b) El listado de funciones a coordinar es amplio, pero la Ley 7/ 85 ha reducido notablemente las competencias de las Diputaciones (art. 36), ejerciéndose en la actualidad la mayor parte de las materias o funciones coordinadas a título transitorio (Disposición Transitoria II), hasta que la Ley de Gobierno Local Valenciana y las leyes sectoriales del Estado o de la Generalitat completen su arco competencial.

c) Las facultades de coordinación se articulan a través de las directrices que determine el Consell (art. $4 .^{\circ}$ ), que contendrán los criterios generales, bases de actuación, instrumentos orgánicos y funcionales con la determinación de objetivos y prioridades (artículo $5^{\circ}$ ).

En resumen, la Ley de Coordinación de Diputaciones no sólo es constitucional, sino más restrictiva de lo que posteriormente ha establecido la Ley $7 / 85$ en casi todas sus determinaciones materiales y formales.

(29) Baena def Alcázar, Mariano: Curso de Ciencia de la Administración, t. I, Tecnos, Madrid, 1985, pág. 291 y sigs.

(30) La citada sentencia declara la nulidad de los párrafos 2 y 3 del artículo 12, lo cual sólo afecta a parte de uno de los mecanismos de control que se establecen en la citada Ley. 
3. OtRas tÉCNICAS DE COORDINACIÓN

El artículo 63 LRBRL señala que corresponde la decisión final al Estado o a la Comunidad Autónoma en aquellas materias que por su naturaleza sea muy difícil o inconveniente una asignación diferenciada de facultades decisorias, pero en estos casos se asegurará la participación de las Entidades locales en las actuaciones o procedimientos conjuntos, según disponga la Ley estatal o regional.

Este precepto legal habilita o apodera para articular mediante Ley otras técnicas relacionales distintas a las que se establezcan en los Planes sectoriales del artículo 59 LRBRL, o en las Directrices de coordinación del artículo $4 .^{\circ}$ de la Ley de Coordinación de las Diputaciones.

Por ello, puede articularse en distintas técnicas como la audiencia previa (así para crear o suprimir Municipios o alterar términos municipales), los informes preceptivos $y$ vinculantes (como las licencias en suelo no urbanizable, o las licencias de actividades calificadas), los informes previos (caso de determinadas concesiones estatales), las aprobaciones sucesivas (caso de los Planes Generales de Ordenación Urbana), e incluso la participación en órganos mixtos (caso de los Planes Provinciales de Cooperación).

En definitiva, será la Ley estatal o regional la que concretará el cauce concreto que asegure la participación de los Entes locales. Participación que la LRBRL ya intenta garantizar en algunos de sus preceptos: artículos $13,25,36,58 \ldots$ (31).

\section{LAS RELACIONES DE COLISION}

Las Entidades locales pueden decidir, por entenderlo así, que la satisfacción de los intereses de su comunidad local se consigue no realizando una determinada conducta o no prestando un servicio, o bien llevando a cabo una gestión que va más allá de sus atribuciones legales.

En ambos casos pueden, eventualmente, lesionarse los intereses comunitarios o generales, pero la satisfacción de éstos se garantiza (32) a través de los mecanismos que pasamos a analizar.

(31) Publicaciones Abella, op. cit., pág. 492.

(32) Climent Barbera, Juan: Legislación..., cit., pág. 223. 


\section{Por conducta Pasiva}

La Administración puede ejecutar subsidiariamente aquellas obligaciones de hacer no personalísimas que deriven de actos administrativos y se impongan a particulares, cuando éstos incumplan dicha obligación (arts. 104 y 106 LPA).

Se trata de uno de los privilegios de los que goza la Administración: el privilegio de autotutela (33), que le exonera de acudir a los Tribunales para conseguir el cumplimiento de sus resoluciones administrativas, que deriva de la presunción iuris tantum de legalidad de sus actuaciones.

El artículo 60 LRBRL articula analógicamente la facultad del Estado y de las CC.AA. de ejecutar subsidiariamente obligaciones impuestas a las Entidades locales que deriven directamente de la Ley.

Supone una novedad la regulación de una cláusula general de estas características, y se justifica tanto en la necesidad de dar cum. plimiento a los intereses generales y comunitarios, como en la inadecuada respuesta que proporcionan los Tribunales al resolver estos conflictos (34), fundamentalmente por la lentitud de sus actuaciones.

De todos modos, las Entidades locales podrán recurrir ante la jurisdicción contenciosa los acuerdos por los que se decide la ejecución subsidiaria, por lo que, en definitiva, a éstos corresponde la fiscalización última de este tipo de situaciones.

Entendemos que puede afectar tanto a competencias propias (35) como compartidas (36) de las Entidades locales, ya que la obligación incumplida deriva directamente de la Ley, pero en la doctrina la cuestión no es pacífica. Eventualmente puede establecerse este control en el ejercicio de competencias delegadas, de conformidad con el artículo 7-3. ${ }^{\circ}$ LRBRL, pues siempre será preferible a la revocación de la delegación.

Respecto a los requisitos procedimentales y materiales que deben seguirse para proceder a la ejecución subsidiaria, tenemos:

a) Procedimentales. Ha de formularse un requerimiento for-

(33) Garcfa de Enterrfa, Eduardo, y Tomás-Ramón Fernández: Curso de Derecho administrativo, t. I, Civitas, Madrid, 1980, pág. 654 y sigs.

(34) Alvarez Rico, op. cit., pág. 191.

(35) Publicaciones Abella, cit., pág. 479.

(36) Garcfa-Escudero Marouez, Piedad, y Pendas Garcfa, Benigno, op. cit., pág. 279. 
mal en tal sentido que concederá el plazo no inferior a un mes para remediar voluntariamente la situación. Si ello no se consigue deberá tomarse acuerdo que se notificará a la Entidad local.

b) Materiales. Básicamente son:

a) Ha de constatarse el incumplimiento de la obligación de hacer.

b) La obligación ha de derivar directamente de Ley formal, y tener cobertura económica garantizada.

c) El incumplimiento ha de afectar el ejercicio de competencias estatales o regionales, $y$

d) Las medidas que se adopten serán únicamente las necesarias para garantizar la ejecución.

Por último, hay que constatar que de la ejecución subsidiaria deriva la obligación de la Entidad local de sufragar los gastos, directamente o mediante compensación de créditos, por lo que en definitiva transforma la obligación en deuda pecuniaria (37).

\section{Por CONDUCTA ACTIVA}

La gestión gravemente dañosa para los intereses generales que implique el incumplimiento de sus obligaciones constitucionales puede producir la disolución de los órganos de gobierno de las Entidades locales por acuerdo del Consejo de Ministros, previo acuerdo favorable del Senado, informe de la Comisión Nacional de Administración Local, y conocimiento del Gobierno regional (artículos 61 y $118-1 .^{\circ} . c$. LRBRL).

Se trata, obviamente, de la máxima facultad de control sobre las Entidades locales, pudiendo adoptar la iniciativa del procedimiento tanto el Gobierno de la Nación como el Gobierno regional, aunque la decisión sólo corresponde al primero.

Esta medida fue muy duramente criticada en la discusión parlamentaria de la Ley $7 / 85$ (38), aunque la STC de 2 de febrero de 1981, la declara constitucional (39).

(37) GaRcí de ENTERRfa, Eduardo, y Tomás-Ramón FernándeZ, op. cit., pág. 671.

(38) El señor Carro Martinez califica el artículo 61 de la ajoya de inconstitucionalidad», «verdadero exabrupto constitucional». Diario de Sesiones del Congreso de los Diputados, 15-11-84, núm. 166, pág. 7536.

(39) El TC admite la inconstitucionalidad de la posibilidad de disolución gubernativa de la legislación anterior, pero admite la constitucionalidad en los supuestos de agestión gravamente dañosa para los intereses generales», en el Fundamento jurídico 10.D, de la sentencia citada. 
Se dice que el artículo 61 LRBRL está inspirado en el artículo 155 de la CE y que tiene una excepcional relevancia (40), como excepcional será su aplicación al exigirse concatenadamente que se produzca una gestión - por tanto, continuada - gravemente dañosa para los intereses generales, y que al mismo tiempo suponga el incumplimiento de sus obligaciones constitucionales.

Por lo demás, es inexplicable que no se haya previsto un requerimiento formal al Presidente de la Entidad antes o una vez iniciado el expediente, y creemos que este procedimiento sólo será de aplicación en situaciones de crisis políticas locales.

En efecto, los Partidos políticos son instrumento fundamental de participación política (art. 6..$^{\circ} \mathrm{CE}$ ), y las Entidades locales articulan su funcionamiento interno a partir de los Grupos políticos (art. 23 ROF). Si pensamos que una vez disuelta la Entidad local . nada impide que las mismas personas físicas se vuelvan a presentar a las elecciones y salgan reelegidas, el artículo 61 LRBRL quedaría vacío de contenido si no entendemos que contiene una llamada a los Partidos políticos para que reconduzcan la crisis institucional producida a nivel local (41).

\section{CONCLUSIONES}

1. Las relaciones interadministrativas reguladas en el Capítulo II del Título $\mathrm{V}$ de la Ley $7 / 85$ se justifican tanto por la configuración de un Estado con múltiples centros dotados de poder públicoadministrativo, como por la necesidad constitucional (art. $103 \mathrm{CE}$ ) y legal (art. 6..$^{\circ}$ LRBRL) de conseguir la máxima eficacia en la acción pública que desarrollan las distintas Administraciones.

2. Los rasgos básicos que explican el modo en que se articulan las relaciones interadministrativas son:

a) La libertad de los Entes locales dimanante de su autonomía, con las lógicas limitaciones que derivan de la existencia de intereses superiores y de su capacidad de gestión.

(40) Garcfa-Escudero Maroulz, Piedad, y Pendas Garcta, Benigno, op. cit., pág. 280.

(41) a... la función de los partidos, en tanto que organizaciones políticas dirigentes de la sociedad, es proporcionar a los electores las ofertas de listas de personas entre las cuales han de elegir a sus representantes... bien entendido que en la mayoría de los sistemas electorales el pueblo elige entre listas y no entre personas, es decir, entre partidos y no entre individuos...». Garcta-PeLAYo, Manuel: El Estado de Partidos, Alianza Editorial, Madrid, 1986, pág. 81. 

cias, $\mathrm{y}$

b) El respeto al ejercicio legítimo de las propias competen-

c) Los mecanismos de información que la LRBRL desea y quiere de forma recíproca y constante, y que se articulan como un derecho-deber.

3. Las Relaciones de Cooperación son la regla general en el marco de la Ley. Se articulan a través de múltiples técnicas relacionales, y la existencia actual de dos órganos consultivos con competencia general; uno a nivel estatal, la Comisión Nacional de Administración Local, y otro a nivel autonómico, el Consell Valencià d'Administració Local.

4. Las Relaciones de Coordinación sólo pueden establecerse por excepción cuando es insuficiente la colaboración voluntaria, a través de Ley, y cumpliendo determinados requisitos.

En la Comunidad Valenciana la coordinación de la Generalitat con las Diputaciones cuenta con una Ley regional específica sumamente respetuosa con la LRBRL y con las competencias provinciales, la mayoría de ellas ejercidas actualmente a título transitorio.

5. Las Relaciones de Conflicto o Colisión se solucionan a través del control de legalidad ejercido sobre los actos y acuerdos de las Entidades locales (que no son objeto de este estudio), a través de la ejecución subsidiaria de las obligaciones locales en determinados casos, y a través de la disolución de sus órganos de gobierno, explicable tan sólo ante situaciones de crisis políticas locales. 